\title{
Role of cervical ultrasound in prediction of preterm labor
}

\author{
Samihana Dhakal', Shripad Hebbar² \\ 'Maternity Hospital, Thapathali, Kathmandu, Nepal \\ ${ }^{2}$ Dept. of Obstetrics and Gynecology, Kasturba Medical College, Manipal, India
}

\begin{abstract}
Aim: To compare the difference in the cervical length measured digitally or by transabdominal and transvaginal sonogram examination for prediction of preterm labour

Method: This was a prospective randomized, controlled study in the Department of Obstetrics and Gynaecology at TMA Pai Hospital, Udupi from March 2001 to May 2002 where 200 women coming for routine antenatal care were recruited for the study. A total of 168 women were evaluated, out of which 145 were control group and 23 cases of threatened preterm labor formed study group.

Results: The mean length of cervix measured by TVS at 20- 24 wks of pregnancy was $3.87 \mathrm{~cm}$. There after there was a slight decrease in the length mainly towards term and or 36 wks of pregnancy i.e. $3.27 \mathrm{~cm}$. Cervical length measured on an average $0.8 \mathrm{~cm}$ more than TVS $(4.9 \mathrm{CM}$ versus $3.52 \mathrm{~cm})$ Similarly digital examination of cervix yielded shorter length, compared to TVS measurement $(2.86 \mathrm{~cm}$ versus $3.5 \mathrm{~cm})$.

Conclusion: This study has shown TVS is a simple tool for prediction of preterm labour as decrease in cervical length was observed in women with threatened preterm labor $(2.34 \mathrm{~cm})$ and this decrease was statistically significant compared to that of the control $(3.7 \mathrm{~cm})$.
\end{abstract}

Key words: Trans abdominal, transvaginal, preterm labour

\section{Introduction}

Preterm labour accounts for less than $10 \%$ of pregnancies and $75 \%$ of all neonatal deaths. Efforts to forecast preterm labour to reduce perinatal morbidity and mortality have been hindered by the lack of a significant correlation of preterm labour with age, previous spontaneous vaginal delivery, tocolytic therapy or history of preterm labour ${ }^{1}$. It is known however that cervix plays an important role in pregnancy outcome. Cervical ripening is the first sign of preterm labour, short cervix hence being a risk factor for preterm labour and delivery. Several studies have shown increased risk of preterm delivery among women with cervical effacement ${ }^{2-4}$ Sonographic evaluation of cervix, determined by transabdominal, transvaginal and transperineal scaning has a significant role to predict preterm labour. As this is more precise but less invasive procedure as compared to digital assessment. Latter having limitation to palpate the supravaginal portion of cervix thus underestimated the cervical length confirmed from sonography. ${ }^{6}$ Premature rupture of membrane was more common with women who had repeated pelvic examination. ${ }^{?}$

Disadvantages of Transabdominal Sonography (TAS) are requirement of full bladder for adequate visualization of cervix while over distention of the bladder is found to compresses the lower uterine segment, lengthening the cervix. Even in the absence of over distention there appears to be a linear increase in cervical length with increasing bladder volume, which gives false assurance of a long and competent cervix. This limitation can be overcome by using transvaginal and translabial approach. Transvaginal Sonogram is a gold standard for the measurements of cervix where bladder as confounding factor can be removed. ${ }^{8}$

Correspondence

Dr. Samjhan Dhakal, MD,

Maternity Hospital

Email:dhakal_samjhana@hotmail.com 
In this study attempts have been made to evaluate total length of cervix, by digital examination, transabdominal and transvaginal sonogram in pregnancy for prediction of preterm labour.

\section{Methodology}

This was a prospective randomized controlled study in the Department of obstetrics and Gynaecology at TMA Pai Hospital, Udupi from March 2001 to may 2002.

The inclusion criteria were as follows: Singleton live pregnancies at $20 \mathrm{wks}$ of gestation with cervical length $>2 \mathrm{~cm}$; regardless of parity and bad obstetric history. Two hundred women attending antenatal care were recruited for study after satisfying the inclusion criteria. Exclusion criteria were history of first trimester bleeding, presence of uterine malformations, fibroid, medical illness which may influence the pregnancy, congenital malformation of fetus, twins, placenta previa.

\section{Procedural steps}

Length of the cervix was measured by digital examination, TAS, TVS.

First of all digital examination was done and cervical findings were noted. Then TAS was preformed by using ATL ultramark 4 machines. Cervical length was measured with a $3.5 \mathrm{MHz}$ curvilinear probe in a partially filled bladder. The cervical canal was visualized from external Os to internal Os. Serial scans were taken. Similarly Transvaginal cervical measurements were taken with a $5 \mathrm{MHz}$ vaginal probe.
The measurements were taken twice in sagital plane by each method and the mean of the two measurements were taken from each method. The initial scan was done at 20-24 wks of pregnancy and it was repeated at least on one occasion between 28-32 wks of pregnancy. In patients with symptoms of threatened preterm, it was again repeated at $36 \mathrm{wks}$ of pregnancy.

All the patients were followed up till delivery. Data were analyzed with Microsoft, SPSS statistical package. Statistical significance was calculated by using chi square and student $\mathrm{t}$-test.

\section{Results}

Out of 200 women, 24 women were lost for follow up and on remaining 176 women; only 168 women were available for final analysis because in 8 women pregnancy had to be iatrogenically terminated before term for antenatal complications like intra uterine growth retardation (IUGR), oligohydramnios, severe pregnancy induced hypertension (PIH) and eclampsia.

Of these 168 women, threatened preterm labour occurred in 23 [(13) delivered before 37 completed weeks of gestation; (10) cases had term delivery after successfully treatment with tocolytics and bed rest as their pregnancy were around 34 wks gestation at the initial presentation.

It is seen that the cervical length measurement at two different period gestation 20-24 weeks or 28-30 weeks using TVS falls in the middle between digital and TAS measurement.

Table I. Cervical measurements made by digital examination and TVS

\begin{tabular}{|c|c|c|c|c|c|c|c|c|}
\hline \multicolumn{3}{|c|}{ Gestation Weeks 20 - 24} & $\begin{array}{l}\text { "t" \& "p" } \\
\text { values }\end{array}$ & Significance & \multicolumn{2}{|c|}{$\begin{array}{c}\text { Gestation } \\
\text { weeks } 28-32\end{array}$} & $\begin{array}{l}\text { "t" \& "p" } \\
\text { values }\end{array}$ & Significance \\
\hline & & Digital & TVS & & & & Digital & TVS \\
\hline Mean $(\mathrm{cm})$ & 2.86 & 3.52 & $' t '=21.11$ & Yes & $2-84$ & 3.41 & $' t '=18.99$ & Yes \\
\hline S.D. & 0.31 & 0.60 & $\mathrm{P}<0.01$ & & 0.32 & 0.61 & $\mathrm{P}<0.01$ & \\
\hline Significance & & & yes & & & & yes & \\
\hline
\end{tabular}

Table 2. Cervical measurements by transabdominal (TAS) and TVS

\begin{tabular}{|c|c|c|c|c|c|c|c|c|}
\hline \multicolumn{3}{|c|}{ Gestation Weeks $20-24$} & $\begin{array}{c}\text { "t" \& “p" } \\
\text { values }\end{array}$ & Significance & \multicolumn{2}{|c|}{$\begin{array}{c}\text { Gestation } \\
\text { weeks } 28-32\end{array}$} & \multirow{2}{*}{$\begin{array}{c}\begin{array}{c}\text { “t” \& “p” } \\
\text { values }\end{array} \\
\text { TAS }\end{array}$} & \multirow{2}{*}{$\begin{array}{c}\text { Significance } \\
\text { TVS }\end{array}$} \\
\hline & & TAS & TVS & & & & & \\
\hline Mean $(\mathrm{cm})$ & 4.31 & 3.52 & $' \mathrm{t}$ ' $=24.03$ & Yes & 4.32 & 3.41 & $' \mathrm{t} '=25.47$ & Yes \\
\hline S.D. & 0.97 & 0.60 & $\mathrm{P}<0.01$ & & 0.96 & 0.61 & $\mathrm{P}<0.01$ & \\
\hline
\end{tabular}


The cervix appears to be shortest on digital examination and longest in transabdominal scan.(Table1-2). There is statistical significance of the measurements.

In table 3 , the mean cervical parameter measurements obtained by TVS in threatened preterm labour and control group has shown statistical significance when
Cervical length at midtrimester had reasonably good sensitivity $(65 \%),(99 \%)$, positive predictive value $(83 \%)$ and negative predictive value $(95 \%)$ at cut off value of $2.5 \mathrm{~cm}$.

The risk of preterm labour was $60 \%, 50 \%, 20 \%$ and $0.7 \%$ at cervical measurement of $2.0-2.2 \mathrm{~cm}, 2.2-2.4 \mathrm{~cm}$,

Table 3. Comparison of cervical length measurement using TVS in threatened preterm labour and control

\begin{tabular}{l|c|c|c|c|c|c}
\hline $\begin{array}{c}\text { Cervical parameter in } \\
\text { gestational weeks }\end{array}$ & $\begin{array}{c}\text { Threatened preterm } \\
(\mathrm{n}=23)\end{array}$ & \multicolumn{2}{|c|}{ Control (n=145) } & \multicolumn{2}{|c}{ Statistical significance } \\
\hline & Mean in (cms) & S.D & Mean (in cms) & S.D & t-value & $\mathrm{p}$ \\
$20-24$ & 2.34 & 0.46 & 3.70 & 0.40 & 23.8 & $(\mathrm{p}<0.05)$ \\
$28-32$ & 2.30 & 0.40 & 3.59 & 0.44 & 23.1 & $(\mathrm{p}<0.05)$ \\
\hline
\end{tabular}

$\mathrm{T}$ test for independent group was used to analyze data. Lower values were seen in threatened preterm labour group both at second and third trimester (period of gestation: 20-24 weeks and 28-32 weeks).

\section{Discussion}

The mean length of cervix at 20-24 wks of pregnancy was $3.87 \mathrm{~cm}$ by TVS. There after there was a constant decrease in length mainly towards term i.e. $3.27 \mathrm{~cm}$ around 36 wks. Similar observation was found in a study done by TR Verma ${ }^{10}$ in pregnancy at 10 wks to 36 weeks.

By TAS cervical length measured $0.8 \mathrm{~cm}$ on an average, which was more than TVS $(4.31 \mathrm{~cm}$ vs $3.52 \mathrm{~cm})$. Anderson ${ }^{11}$ et al has reported the same findings. G. Marc Jackson ${ }^{12}$ in his study has found cervical length was underestimated by digital examination with respective measurement.

Similarly digital examination of cervix yielded shorter length, compared to TVS measurement $(2.86 \mathrm{~cm}$ vs 3.52 $\mathrm{cm})$ and it was $0.7 \mathrm{~cm}$ less.

There was statistically significant difference in the mean length of whole cervix between control and case (those who had symptoms of premature contraction) ie $3.70 \mathrm{~cm}$ Vs $2.34 \mathrm{~cm}$, Similar differences were observed between control and those who had preterm labour $(3.62 \mathrm{~cm}$ vs $2.30 \mathrm{~cm})$.
$2.4-2.6 \mathrm{~cm}, 2.6-2.8 \mathrm{~cm}$. Survival analysis showed that significant proportion of patients deliver before 37 weeks when cervical length is less than $2.5 \mathrm{~cm}$ and major proportion continued their pregnancies till term when cervical length measured more than $2.5 \mathrm{~cm}$ when it is $>2.5 \mathrm{~cm}$.

\section{Conclusion}

TVS is a simple tool of great diagnostic importance in prediction of preterm labour. Cervical length measurement by TVS has acceptable performance at both gestational age (20-24wks and 28-32wks).

\section{References}

1. Anderson HF, Nugent CE, Wanty SD, Hayashi $\mathrm{RH}$. Prediction of risk for preterm delivery by ultrasonographic measurement of cervical length. Am J Obstetrics and Gynecology 1990; 163: 859867.

2. Papiernik E, Bour J, Collin D, Winisdoerffer G, Dreyfus J. Precocious Cervical ripening and preterm labour. Obstet Gynecol 1986; 67:238.

3. Sonek JD. Cervical length may change during ultrasonographic examination. Am J Obstet and Gynecology1990;162:1356-1357. 
4. Owen J, Goldenberg L R, Davis O R, Kisk A K, Copper RL. Evaluation of a risk scoring system as a predictor of preterm birth in an indigent population. Am J Obstet and Gynecology 1990; 163: 868-872.

5. Berghella V et al. Prediction of preterm labour with TVS of cervix in patient with high risk pregnancy. Am J Obstet and Gynecology 1999;181:809-815.

6. Jackson G M, Ludmir J, Bader TJ. The accuracy of digital examination and ultrasound in the evaluation of cervical length. Obstetrics and Gynecology 1992; 79: 214-218.

7. Brown E J, Lieutenant Col, Mc Gary, Thieme A, Shah D M, Fleischer CA, Boehan H F. Transabdominal and Transvaginal endosonography; Evaluation of the cervix and lower uterine segment in pregnancy. Am J Obstet and Gynecology 1986; 155:721-726.
8. Lenihan JP Jr. Relationship of antepartum pelvic examination to premature rupture of membrane. Obstet Gynecol 1984;63:3390.

9. Sonek JD, Iam JD, Blumenfeld M, Johonson F, Landon M, Gabbes. Measurment of cervical length in pregnancy. Comparision between vaginal ultrasonography and digital examination. Obstet and Gynecology 1990;76:172-175.

10. Varma TR, Patel RH, Pilai U. Ultrasonographic assessment of cervix in normal pregnancy. Acta Obstetrics and Gynecology Scand 1986;65:229233.

11. Anderson HF. Transvaginal and Transabdominal Ultrasonography of the uterine cervix during pregnancy J Clin Ultrasound1991;19:77-83.

12. Jackson GM, Ludmir J, Bader TJ. The accuracy of digital examination and ultrasound in the evaluation of cervical length. Obstetrics and Gynecology1992;79:214-218 